\title{
thelomi
}

Feature Climate Change

\section{Opportunity knocks: health wins from action on global warming}

BMJ 2009; 339 doi: http://dx.doi.org/10.1136/bmj.b4947 (Published 25 November 2009) Cite this as: BMJ 2009;339:b4947

\author{
lan Roberts, professor of epidemiology and public health \\ ${ }^{1}$ London School of Hygiene and Tropical Medicine, London
}

ian.roberts@lshtm.ac.uk

Will health make it on to the agenda at next month's United Nations climate change talks in Copenhagen? Concerned that the links between fossil fuel energy use and human health are being overlooked, lan Roberts talked to England's chief medical officer to find out what he thinks doctors and health services in high income countries could be doing. He also canvases expert opinion from Bangladesh, where many people are already experiencing the health effects of climate change

Evidence of the health benefits of living an environmentally sustainable life continues to stack up. It is clear that we need to use less fossil fuel powered transportation and do more walking and cycling, and that we must consume fewer animal products, which contribute to climate change through methane emissions and deforestation. Since physical inactivity and animal fat consumption are major killers, the benefits of sustainable living seem obvious. But what is less obvious is how health professionals can communicate this to the wider world - to climate change policy makers and to the public. It seems like the health sector has the only good news story in the whole climate change catastrophe, but it is keeping it to itself. How can we tell it? I met with Liam Donaldson to hear his thoughts, but the chief medical officer was lukewarm on the prospect of any easy wins.

"I think this is a classic example of where people just approach the subject with a great deal of commitment and passion and don't perhaps think about a more organised and orchestrated approach to getting where we want to get," he said.

"Doctors can play a big part by pointing out the win-wins, making it clear what health has got to do with it, because certainly when I talk to environmentally based ministers in my travels they don't necessarily see that health has got much to do with it and are quite surprised to see that there is a health angle."

Donaldson believes lessons could be drawn from the tobacco control lobby. "The first thing is to frame the debate in health terms and then mobilise as much support as possible, and then constantly advocate the benefits of change. And to do that I think you need articulate leaders; you need killer stats. A small number of killer statistics is the way that we achieved breakthroughs in smoking particularly."

Donaldson is a fan of "concrete ideas," such as the proposed international framework for dealing with 
climate change called contraction and convergence. This involves sharing out rights to emit carbon dioxide and sets a timetable for when emissions must converge to equal per capita shares. In the convergence phase, wealthy countries would have to make deep cuts even as emissions from poorer countries are increasing. However, once per capita emissions converge, rich and poor alike will have to reduce emissions. The policy allows for emissions entitlements to be traded in order to ease the transition to equal shares, while ensuring that the safe upper limit is not exceeded. High emitting countries like the United Kingdom and the United States would have to buy the unused emissions rights of poor countries, many of which would be in Africa or Asia.

"I think there is nothing better than a concrete idea," says Donaldson. "We've got great success here with the smoke-free public places in tobacco control. It's a very concrete idea, and you have to start off in assessing the degree of public support for it and then how the different points of view balance out."

Donaldson has spoken of his concern about the rising prevalence of obesity and overweight. To prevent rising body mass index we must take on our obesogenic environments, building physical activity back in to our lives and limiting the availability of the energy dense fats and sugars that currently surround us. The links with climate change mitigation are clear, and the word "obesogenic" could easily be replaced with unsustainable. But although there have been many well intentioned efforts to change the way we move and eat, there is little evidence of progress. More radical changes are required than have been achieved to date. These changes will face powerful opposition. Is public health up to the task?

\section{Leading without lecturing}

"I think it's absolutely prime territory for public health, but it's always been the difficult area for people to effect change," says Donaldson. But shouldn't the Department of Health take the lead by developing a low carbon public health strategy for the country? "Well we have a strategy for the NHS in relation to climate change as you know, and that's being very well led by David Pencheon [director of the NHS Sustainable Development Unit]. [But this issue] does go beyond-way beyond-what we ought to be doing to make the NHS a more effective contributor to carbon reduction. So I do think I agree with you it's something we should look at."

But Donaldson doesn't think that the penny has dropped. One problem is the tension between public health leadership, on the one hand, and being at the mercy of public opinion on the other. For example, Donaldson's proposals on minimum pricing on alcohol made sound sense from a public health perspective but did not seem to be politically acceptable, presumably because the government was worried that many voters like getting blind drunk on a Friday night. But how does public health deal with that problem of having to pander to voters' wishes to consume, whether underpriced alcohol or underpriced fossil fuels?

For the chief medical officer it's all about timing: "I think that on alcohol, it was just the political timing. It was in the middle of a credit crunch where the perception-l think wrongly-was that it would be bad both for people's pleasures and for industry to do this at this particular time. We did get the concession from the government that they haven't ruled it out, which was good news from my point of view."

Nevertheless, he believes the public can be receptive to a clear steer on health issues. "Sometimes governments are frightened to do things because of not wanting to be seen to be the nanny state-but when focus groups and opinion polls are done, the public actually seems to want the government to intervene on more things." He cites minimum pricing on alcohol and the mailbag of letters he has 
received from parents concerned about binge drinking among young people.

"And I know that's not scientific, but it just tells me there is quite a silent bedrock of support out there for some of these things." The problem for those promoting the message that a low carbon life is also a healthier one, is that the cause and effect argument is much harder to make than with alcohol and tobacco.

"I think the problem with climate change is I don't know how much the average citizen in this country can get past what I think is a very, very common perception that what is the point of them doing anything when the big polluting countries are still polluting. So when somebody carries their waste out and puts it in the different bins for recycling, what is that going to do when they see China and India and the US? And I think that's again about assembling the argument so that they have a direct relevance to people, because otherwise they'll all agree with the things that we're saying, they'll agree with our analysis, but they'll feel disempowered to directly contribute to it," he says.

And the same could be said of frontline doctors: "We have to recognise that they will not see this as an issue for them beyond possibly what their own organisation can do."

But isn't the point about health co-benefits the fact that mitigating climate change might not necessarily mean such a sacrifice after all, and that people will be the beneficiaries of many of the changes? Donaldson is not so sure. "I wonder if there comes a point that Joe Public might think we're just bending the climate change argument to a mainstream health cause? In other words we're somehow making climate change fit into it, because I think conceptually people would have to work hard to see the link between an obesogenic environment and climate change and greenhouse gases and carbon reduction. That's my only thought on it. I think the difference between a public health analysis and a public perception is a very big gap sometimes, and people can't necessarily see the connection and can't see the win-wins in the way that we can."

If Donaldson is right then health professionals in Britain clearly have their work cut out. But on the other side of the world the connection between climate change and health is obvious (see box).

\section{Reality of climate change}

For doctors in Bangladesh the link between use of fossil fuels and health is clear. Bangladesh tops the 2009 global climate risk index with threats from storms, floods, and heatwaves. People living in southern Bangladesh, where the land is only centimetres higher than sea level, are particularly vulnerable. There have already been reports that crop yields are falling because of increased salinity. I asked Professor Ruhul Haque, minister for health and family welfare of the People's Republic of Bangladesh what doctors could do to help.

lan Roberts: How do you think that climate change will affect public health in your country?

Ruhul Haque: As you know climate change is already affecting us in the country. And as this brings cyclones and floods to the country, obviously this mostly affects the poorer class of people who live in rather shanty places and their houses are not good. So this is one of the things that is influencing health service delivery to the poor.

IR: Is it affecting them now?

RH: Poverty, climate change, and disasters make it very difficult for the health service to deliver a 
system. We have special plans for people in hard to reach areas, especially those affected by cyclones and floods, etc. We have mobile teams with boats. So definitely the climate will sort of influence the service delivery system, and especially to the vulnerable people. We are quite aware of this, and we have tried to protect this vulnerable group as best as we can.

IR: What do you think health professionals should be doing to lessen the health effects of climate change?

RH: They should have more training basically, because health professionals are trained to deal with acute myocardial infarction or, say, a fractured tibia and they are not often trained very well to deal with the basic primary needs of the group of people who are most vulnerable. Sometimes it's diarrhoea or other problems due to climate change. So I think it's not only the doctors but the paramedics and people who are delivering the health service to this community who should be better trained. We are already better prepared, and disaster management is in a good state in our country, but I'm sure we can improve on this situation. A special requirement after disaster in our country is a need of water for sanitation and drinking.

IR: But in as much as climate change will seriously affect people's health, what role do you think the medical community has in making its voice heard in, for example, climate change negotiations in Copenhagen at the end of this year?

RH: I think that is a very important question. It is countries like ours that are most affected, but the fault is mostly with the developed countries. We [in affected countries] should be speaking in a common voice, in a loud voice so that the developed nations can understand-and help the people who are suffering as a result of climate change.

IR: You've made a very important point here, that it's the past emissions from rich countries that have caused most of the climate change so far and that it's people in countries like Bangladesh who are suffering the consequences. So what should be the responsibilities of health professionals in rich countries?

RH: I have lived in the West, and for a long time in the UK-and I think it may not be apparent to health professionals that this is an important issue for them to raise for this vulnerable group of people in the world. I also think the system of carbon allowances that I read about and see in the media, is a really important issue and we can make this issue heard to the world.

\section{Notes}

Cite this as: BMJ 2009;339:b4947

\section{Footnotes}

- Competing interests: The author has completed the unified competing interest form at www.icmje.org/coi_disclosure.pdf (available on request from the corresponding author) and declares (1) no financial support for the submitted work from anyone other than their employer; (2) no financial relationships with commercial entities that might have an interest in the submitted work; (3) no spouses, partners, or children with relationships with commercial entities that might have an interest in the submitted work; and (4) no non-financial interests that may be relevant to 
the submitted work.

- Provenance and peer review: Commissioned; not externally peer reviewed. 